$\bullet$

NORMAN FRIEDMAN

Tradução de Marta Cavalcante de Barros

\title{
O que faz
}

\section{um conto}

\section{ser curto?}


pesar de o conto como uma categoria li-

terária obter mais atenção do que o esperado em textos utilizados em sala de aula e em compêndios de escritores, ele continua - conspurcado pelo comércio e amaldiçoado pela condescendência - ficando em quarto lugar depois da poesia, do drama e do romance em livros e revistas dedicados à crítica teórica mais séria.É na esperança de traçar o início de um caminho em direção à avaliação do conto como uma arte nobre e digna que devo empreender um ataque ao problema principal desse tipo de composição: o de sua brevidade.

Mas a questão não consiste apenas em definir "brevidade", ou fixar os limites máximos ou mínimos em relação ao número de palavras que um trabalho de ficção pode ter para ser denominado conto. Obom senso diz que, embora as linhas divisórias não possam - nem precisem - ser determinadas, nós podemos muito bem, apesar das exceções, distinguir entre uma narrativa longa, curta ou de tamanho médio. Logo, não iremos falar sobre extensão em termos estritamente quantitativos, pois a maioria de nós sabe o que é um conto e podemos tirar de nossas prateleiras, a qualquer momento sem perceber, uma dúzia de antologias contendo histórias de diversos tamanhos - todas chamadas de "curtas". Discutir sobre limites é quase sempre infrutífero e esta é uma boa razão para não se tentar. Irei simplesmente assumir, sem precisar de provas, que os exemplos discutidos neste ensaio como espécimes do gênero são, de fato, considerados como contos.

Também não está em questão definir uma forma diferente, se por forma queremos dizer, como geralmente fazemos, certos materiais agrupados para conseguir um determinado efeito, pois os materiais e sua organização em um conto diferem dos de um romance em grau mas não em gênero. Dizer, como ocorre freqüentemente, que a narrativa curta é diferente da longa devido, principalmente, a sua maior unidade é certamente levantar de imediato inúmeras questões. Um sobrevivente fossilizado da 
estética de Poe, essa noção confunde totalidade com uniformidade, unidade com intensidade. Se unidade implica que todas as partes estão relacionadas por um princípio organizador global, certamente não existe razão por que um conto deva ter mais unidade do que um romance, apesar de este poder ter naturalmente menos partes para unificar - uma questão que iremos examinar no seu devido momento.

Sequer podemos afirmar que um conto não pode contemplar o desenvolvimento de uma personagem, como também muitas vezes é feito; ou mesmo que focaliza muito mais o clímax do que o curso dos acontecimentos, porque, na verdade, o fato é que muitas histórias retratam uma personagem em processo de mudança - por exemplo, "The Short Happy Life of Francis Macomber" ("A Vida Curta e Feliz de Francis Macomber"), de Hemingway; ou mesmo “Barn Burning”, de Faulkner. De modo similar, não há razão por que uma história não possa lidar com mudança de mentalidade como no conto de Steele, "How Beautiful With Shoes"; ou mesmo com uma mudança de destino como em "Babylon Revisted" ("Regresso à Babilônia"), de Fitzgerald (claro que algumas histórias são estáticas e nós falaremos delas mais adiante). Ainda não podemos afirmar que são histórias mais organizadas em torno de um tema do que os romances, pois algumas de fato o são, como “The Lottery”, de Shirley Jackson; e outras não, como "The Other Two", de Edith Wharton. Um conto pode suscitar suspense e expectação, pena, repugnância, esperança e temor, tanto quanto um romance, e pode resolver todas essas emoções de um modo completo e satisfatório tanto quanto um romance (1).

Há, claro, muita verdade nas aproximações que tecemos acima, mas nenhuma delas consegue incluir todas as possibilidades para ser de fato proveitosa. Certamente contos contêm menos palavras que romances, mas essa medidaé enganosa pois se centra nos sintomas mais do que nas causas; certamente, os contos podem causar um impacto único no leitor, mas esse efeito tem mais a ver com outras questões do que simplesmente a da unidade; e certamente um romance lida muito mais com ações dinâmicas do que um conto, mas há maneiras pelas quais um conto pode engendrar mudanças dentro de sua própria esfera. De modo conciso, a maioria desses princípios é muito prescritiva. Portanto, para se compreender como e por que um conto tende a ser curto, gostaria de propor uma maneira de responder a essas questões que se adequará a todos os exemplos do gênero sem prescrever, de antemão, quais são as características que esse gênero deve apresentar.

Uma história pode ser curta, para começar com uma distinção básica, seja por uma ou pelas duas razões fundamentais: o próprio material pode ser de menor alcance, ou o material, sendo de maior escopo, pode ser reduzido a fim de maximizar o efeito artístico. A primeira razão tem a ver com o objeto da representação, enquanto a segunda, com o modo pelo qual ele é representado. Desse modo, iremos falar sobre o tamanho da ação (que pode ser ampla ou reduzida e que não deve ser confundida com o tamanho da história, que pode ser curta ou longa), e sobre sua estrutura estática ou dinâmica; e, então, sobre quantas de suas partes podem ser incluídas ou omitidas; a escala na qual podem ser mostradas e o ponto de vista pelo qual pode ser contada. Uma história pode ser curta em função de qualquer um desses fatores ou de qualquer combinação, mas visando à clareza e à conveniência iremos tratar de cada um deles separadamente e ilustrar com citações onde for necessário.

Elder Olson nos deu uma série de conceitos bastante úteis para falarmos sobre a questão do tamanho com certo grau de clareza e precisão (2). Um discurso, ele diz, contém uma articulação verbal contínua de um único personagem numa situação fechada; nela, o falante tanto fala consigo mesmo sem interrupção (solilóquio) quanto, se houver outros personagens, eles não podem nem replicar nem fazer entradas e saídas de cena enquanto ele fala (monólogo). Esse é o tipo de ação mostrada em pequenos poemas, comumente chamadas

\footnotetext{
Cf. R. S. Crane, "The Concep of Plot and the Plot of Tom Jones", in R. S. Crane (ed.), Critics and Criticism: Ancient andModern, Chicago, 1952 pp. 616-47; e Theodore $A$ Stroud, "A Critical Approach to Short Story", in Journal of General Education, IX, 1956 pp. 91-100. O ensaio em questão pode ser lido em associação ao de Stroud.

2 Ver: "An Outline of Poetic Theory", in Critics and Criticism, op. cit., pp. 546-66 esp. p. 560
} 
de "líricos", como por exemplo "To His Coy Mistress”, de Marvell; ou mesmo “On First Looking Into Chapman's Homer”, de Keats, e muitos, muitos outros. Uma cena inclui uma cadeia contínua de articulação engendrada entre dois ou mais falantes sendo que um fala com o outro (diálogo) numa situação fechada, enquanto um episódio contém duas ou mais dessas cenas, algumas centradas em torno de um incidente principal. Finalmente, uma trama é um conjunto de dois ou mais episódios. Um conto pode conter, concebivelmente, uma ação de quaisquer desses tamanhos.

Naturalmente, uma ação mais longa, como é a trama de Great Expectations (Grandes Esperanças), apesar de unificada em função de seu tamanho total, contém subações menores, tais como discursos, cenas e episódios, unificados no que se refere a suas proporções específicas; e estas subações menores podem ser, e freqüentemente o são, destacadas por propósitos específicos, como, por exemplo, quando um episódio é extraído de um livro e incluído em uma antologia. Podemos dizer que ações de diferentes tamanhos encaixam as menores nas maiores. No entanto, o ponto é que um discurso, cena ou episódio, que foram elaborados neles mesmos para servir como uma base unificadora de um únicotrabalho completo, precisam ser inteiramente independentes, considerando que num trabalho mais amplo essa independência é parcial, necessariamente contendo elementos que ligam essas partes ao que veio antes e ao que vem depois.

O que faz um autor fazer uma escolha inicial quanto ao tamanho de seu texto, nós podemos apenas supor; exceto pelo fato que ele provavelmente percebe ter uma ação completa e total nela mesma e isso será suficiente como base para um tratamento separado. Assim, esta é uma questão da concepção primeira e tudo o que podemos dizer é que um autor escolhe como tratar ações de diferentes tamanhos porque ele sente, seja por hábito ou escolha deliberada ou mesmo intuição ou alguma combinação, que qualquer ação dada sintetiza tudo o que é relevante para seu propósito. Logo, uma ação de qualquer tamanho pode constituir um todo completo nela mesma, e quanto menor for a ação, mais curta pode ser sua apresentação.

Portanto, as partes relevantes de uma ação, que é total e completa, incluem aqueles incidentes que são necessários para criar e apresentar quaisquer conseqüências necessárias ou prováveis que o autor queira mostrar seu protagonista representando ou sofrendo, e também incidentes tais como estes, na medida em que pode ser útil dispôlos em sua essência. Então, o tamanho dessa ação irá depender do que o autor quer que seu protagonista faça ou sofra e do quanto, correspondentemente, ele deve adentrar nas experiências desse seu protagonista a fim de achar as causas que são necessárias e suficientes para motivar e dar crédito àquela ação. Claramente, uma ação dinâmica pode fazer uso de um número bem maior de causas do que uma ação estática, e uma mudança mais inclusiva irá requerer uma cadeia maior de causa do que uma menos inclusiva. Desse modo, uma ação, seja do tamanho que for, constitui um todo completo sempre que o delicado entrelaçamento de causas e efeitos englobar qualquer coisa que seja suficiente para tornar uma ação compreensível e verossímil.

Um discurso é mais bem mais adequado, obviamente, para conduzir um único momento ou uma breve sucessão de momentos em qualquer cadeia de causa e efeito. Uma resposta imediata, seja estática ou dinâmica, para um estímulo imediatoé uma competência específica da poesia lírica. Em “With Rue My Heart Is Laden”, de Housman, por exemplo, a voz lírica expressa tristeza diante do fato de muitos de seus amigos estarem agora mortos, enquanto em "Stopping By Woods", de Frost, a voz lírica responde a uma misteriosa atração pela floresta escura e cheia de neve, primeiro entregando-se à sua sedução e, depois, resistindo a ela. No primeiro exemplo, temos um único, mas completo, momento de lamentação, enquanto no segundo temos uma mais longa mas igualmente completa sucessão de momentos durante os quais quem fala tenta decidir-se por algo, no sen- 
tido de escolher entre alternativas. Dos dois modos, essas ações particulares são inerentemente pequenas, e qualquer coisa que seja necessária para torná-las claras e verossímeis pode ser incluída num espaço pequeno.

Como resultado, essas ações raramente são tratadas na ficção, mesmo na ficção mais curta. Todos sabemos que os meios da arte poética são especialmente capazes de lidar com esse tipo de coisa de uma maneira muito intensa, e que a prosa narrativa, sendo bastante flexível, é muito mais adequada a ações mais amplas nas quais há mais para ser mostrado. Conheço duas dessas ações em ficção, mas são exceções, como prova a regra. O texto de Dorothy Parker, "A Telephone Call", apresenta uma jovem lutando contra o sofrimento causado por uma previsão angustiante enquanto espera um, já atrasado, telefonema de seu namorado. E isso é tudo o que há: no que nos diz respeito, o conto, como um todo, compreende seu solilóquio interior enquanto ela espera o telefone tocar. De modo similar, o texto de E. B. White, “The Door”, não apresenta nada além de estados mentais contínuos de seu único personagem, apresentado indiretamente pelo modo de narrar e, às vezes, diretamente pelo solilóquio interior - que é mostrado em um estado de incerteza e frustração perante os valores contraditórios da civilização moderna.

Apresentar uma cena única é muito mais viável na ficção curta, apesar de, mesmo nela, os exemplos puros não serem tão comuns como poderíamos supor. A melhor e mais clara amostra com a qual estou familiarizado é "Hills Like White Elephants" ("Colinas Parecendo Elefantes Brancos"), de Ernest Hemingway, que mostra um jovem casal de americanos esperando, numa estação de trem isolada no vale Ebro, o expresso de Barcelona. Exceto pela garçonete que traz suas bebidas, a história gira em torno de um único e contínuo diálogo que ocorre entre o homem e a mulher enquanto esperam. O ponto central dessa história, que lida com uma situação estática,é creio, revelar-nos, pouco a pouco, as causas da difícil situação em que a moça se encontra e através dela incitar nossa compaixão. Tudo indicando não serem casados, esses dois estão se decidindo sobre o aborto do bebê que a moça espera. No entanto, não é essa a razão do pathos da história; antes, este reside no fato de, conforme a conversa progride, ficar mais evidente que o amante não nutre reais sentimentos por ela nem por sua necessidade incipiente de querer levar essa relação a uma consecução típica. Desde que isso seja tudo o que precisamos saber para que um determinado efeito seja obtido, e desde que isso possa ser feito dentro de uma única conversa, foi o que fez Hemingway para unificar essa história tão particular.

$\mathrm{E}$, claro, issoé feito com muita maestria. Por exemplo, temos, já próximos do final: "Ele não disse nada, mas olhou para as malas contra a parede da estação. Nelas havia etiquetas de todos os hotéis nos quais tinham passado as noites". A partir desse pequeno detalhe podemos inferir inúmeras coisas acerca da situação desse casal - a superficialidade de seu relacionamento, seu desapego, seu caráter transitório. Essa alusão a um passado próximo, apesar de não ser formalmente uma parte da ação que está sendo mostrada (na medida em que as causas do pathos são mostradas conforme a cena progride) ajuda a colocar a situação em sua essência na mente do leitor. E notamos como foi engenhosamente incorporado à trama dessa cena sem a intrusão do autor.

O episódio é um tamanho mais comumente encontrado nos contos - de fato, sua freqüência pode nos permitir afirmar que esse é um tipo de ação bem típica com que essa arte lida. “Dez Índios” de Hemingway, por exemplo, contém cinco cenas centradas em torno da descoberta de Nick sobre a infidelidade de sua namorada índia, sua subseqüente depressão e o esquecimento de seu desgosto. Afinal de contas, ele é muito novo para permitir que uma desilusão o afete por mais de algumas horas de uma só vez. Esta é uma ação dinâmica, envolvendo mudanças de intenção e sentimentos, e por essa razão requer - não havendo maiores diferenças - uma ação mais ampla em vez

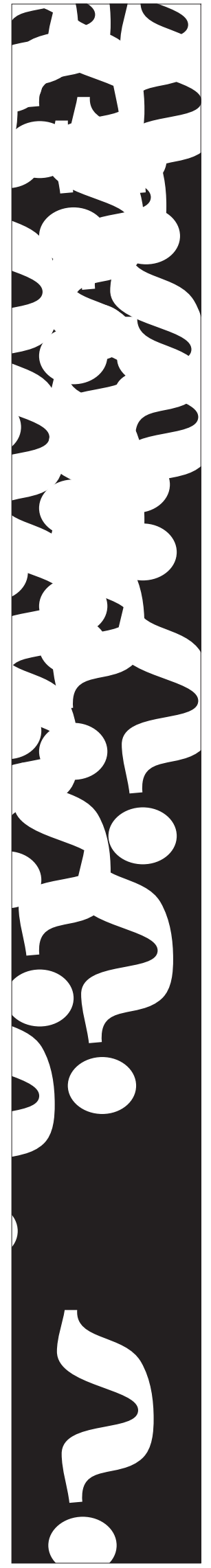




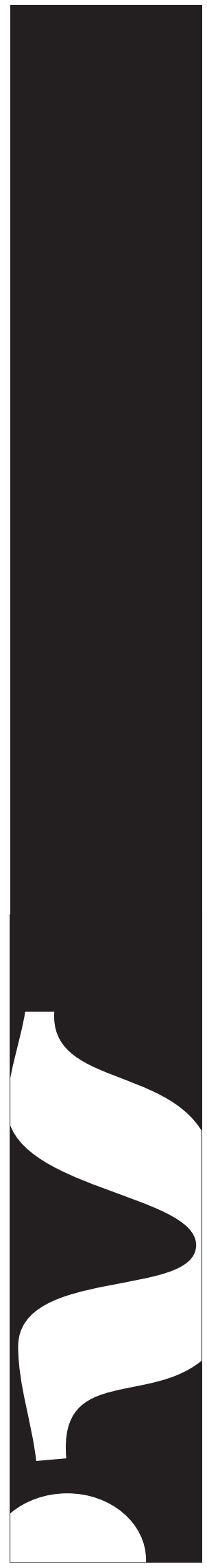

de uma cena única para o estabelecimento de uma cadeia de causa e efeito. No entanto, tudo se passa dentro do período de algumas horas e cada uma das cenas nos aproxima ou nos distancia do único incidente central: 1) Nick volta para casa, já bem tarde, depois da celebração de 4 de julho na cidade, junto com a família Garner, e eles o provocam a respeito de sua namorada índia; 2) eles chegam à casa dos Garner, descarregam a carroça e Nick se dirige sozinho à sua própria casa; 3 ) Nick caminha até sua casa; 4) seu pai lhe dá o jantar e lhe diz como viu Prudie "tendo bons momentos" na floresta com outro rapaz, fazendo Nick ficar triste; 5) Nick vai para a cama sentindo-se infeliz, mas acorda, mais tarde, contente com o som do vento e das ondas, totalmente esquecido de sua tristeza.

Assim, uma cena ou episódio pede menos espaço para ser contada do que uma trama.

Outra questão que se refere ao tamanho é se a ação envolve ou não uma mudança e, se de fato envolver, se essa mudança é fundamental ou secundária, e simples ou complexa. Espero agora que já esteja claro que um conto pode ser estático ou dinâmico, apesar de, como vimos, uma ação estática normalmente requerer menos partes do que uma que é dinâmica e que irá, portanto, normalmente ocupar menos espaço na narrativa. Isso quer dizer que uma história estática simplesmente apresenta seu protagonista em uma ou outra situação e inclui apenas o suficiente para revelar ao leitor a causa ou causas das quais essa situação é conseqüência, enquanto uma história dinâmica conduz seu protagonista através de uma sucessão de duas ou mais situações e, assim, deve incluir muitas etapas causais das quais essas situações são conseqüência.Logo, uma história estática normalmente é mais curta do que uma dinâmica.

Por isso, apesar de nem todos os contos serem estáticos, a maioria das ações estáticas é mais facilmente encontrada nos contos - situações estáticas, expandidas e elaboradas até o tamanho de um romance são comparativamente raras (Mrs.Dallowayé um exemplo). Além disso, há uma correla- ção geral e similar entre ações estáticas e dinâmicas e seus diversos tamanhos. Na ficção, conseguir uma mudança no protagonista em uma única cena ou discurso é possível mas não provável; e estender uma situação estática por um episódio inteiro independente ou uma trama completa é também possível mas igualmente improvável. Eu direi que, como uma regra, a maioria das ações estáticas contém uma cena ou um pequeno episódio.

Outro exemplo de história estática, além do já comentado "White Elephants", é "Sinners" de Sean O'Faolain. Nessa história,é revelada a angústia mental de um padre católico diante das mentiras de uma criada em confissão. Primeiro ele é mostrado se contorcendo, de modo irritado, perante as histórias da moça durante a confissão; e então, depois, gritando, num verdadeiro vexame, quando, por acaso, ele a ouve admitindo suas mentiras em confissão para sua patroa. Seu estado emocional é anunciado na primeira parte da história e confirmado na segunda (por causa das transições há não mais do que duas cenas aqui). Assim, o leitor pode perceber sua frustração e então entendê-la como tendo plena justificativa. E, a fim de atingir tal efeito, o escritor mostrou somente o que ele precisava, duas cenas ou quase e nada mais.

Claro, ele poderia ter continuado com essa história para nos mostrar o cônego passando por uma mudança subseqüente nos sentimentos para melhor; e, nesse caso, ele teria que introduzir toda uma nova linha de causas trabalhando nessa direção e, portanto, o teria tornado mais longo; mas se ele tivesse meramente continuado na mesma linha, ele teria excedido as necessidades de seu efeito. Esse efeito e a quantidade de ação requerida para atingi-lo determinam a brevidade dessa história, quando considerada nela mesma como um trabalho auto-suficiente.

Por outro lado, "Francis Macomber", "Barn Burning", "How Beautiful with Shoes", "Babylon Revisted" e "A Morte de Ivan Ilitch" são contos que compreendem ações dinâmicas. No primeiro conto, um homem covarde finalmente se torna cora- 
joso diante do perigo; no segundo, um jovem decide, finalmente, se opor à destruição vingativa de seu pai da propriedade de seu patrão; no terceiro, uma moça ignorante das montanhas torna-se consciente de que o homem pode ser mais do que um animal; no quarto conto, um bêbado reabilitadoé temporariamente frustrado em seus planos de reconquistar sua filha que fora afastada dele; e no quinto, um homem moribundo vê o vazio de sua vida, verdadeiramente, pela primeira vez. Entretanto, há uma diferença no que se refere à amplitude, mesmo entre ações dinâmicas; em todas, menos na última, há mudanças mínimas, não no sentido de que sejam pouco importantes, ou que suas consequiências não sejam sérias ou de longo alcance, mas mais no sentido de que elas dão movimento e pedem para sua representação apenas um momento da vida dos protagonistas. Logo, uma mudança pequena irá normalmente requerer menor espaço do que uma maior

Novamente aqui pode haver uma correlação geral entre inclusão e o tamanho da ação, pois a maioria das mudanças mínimas irá envolver apenas um episódio, enquanto uma mudança maior irá envolver uma trama completa. Nesse sentido, "A Morte de Ivan Ilitch" tem mais em comum com Grandes Esperanças do que com as outras histórias mencionadas; de fato, esse conto cobre mais aspectos da vida de seu protagonista do que o romance de Dickens. Assim, alguns episódios são estáticos; outros dinâmicos, mas as tramas tendem sempre a ser dinâmicas. Uma das diferenças entre a trama de um conto e a de um romance não precisa estar, como veremos adiante, no tamanho intrínseco de suas ações mas sim no modo pelo qual essas ações são representadas. Nesse sentido, "Ilitch” está, sem dúvida, mais próximo em extensão de um conto do que de um romance.

Por outro lado, não há razão por que uma ação que cobre muitos episódios não possa envolver simplesmente uma mudança mínima. Portanto, temos que distinguir, com base na inclusão, tramas secundárias ou principais (e suponho que um episódio possa lidar com uma mudança importante, mas não acho que isso seja provável). Fitzgerald aponta para essa distinção quando narra as experiências de Dexter Green em "Winter Dreams" ("Sonhos de Inverno"). É com uma daquelas negativas (as misteriosas proibições com as quais a vida é indulgente) e não com sua carreira como um todo de que essa história trata. E, de novo, quase no final da história: "Lembremse, esta história nãoé sua biografia, embora nela perpassem certos acontecimentos que em nada se relacionam com aqueles que ele tinha quando era jovem. Chegávamos agora ao fim de sua descrição e pouco mais temos que dizer do próprio Dexter"(*). Fitzgerald está dizendo, na verdade, que essa determinada história encontra sua unidade tratando apenas dos episódios que são necessários para mostrar ao leitor as causas da fascinação de Dexter por Judy Jones e sua subseqüiente desilusão, e todas as possibilidades juvenis que ela representa em sua mente e, para esse fim, as outras experiências de Dexter (provavelmente suas ousadias nos negócios e coisas parecidas) não são particularmente relevantes aqui. Ele guiou-se, conseqüentemente, em grande parte, por essa escolha original dentre questões tais como por onde começar e terminar, e o quanto incluir ou omitir. É essa limitação, assim como quais fases da vida do protagonista são relevantes para uma determinada mudança, que é responsável pela brevidade da história.

No entanto, a ação de The Great Gatsby (O Grande Gatsby), apesar de ser admiravelmente similar em seu contorno geral, pois cobre a vida toda de Gatsby, é uma trama mais abrangente. A obsessão de Gatsby por Daisy, e pelo que ela representa para ele, consome todos os aspectos de sua carreira e, de fato, no final, custa-lhe sua própria vida. Por isso, a desilusão de Gatsby só pode ser compreendida em função de sua vida como um todo e é por isso que a narrativa de sua história é mais longa do que a de Dexter. Acrescentar outros interesses de Dexter em "Winter Dreams" seria um grande erro artístico assim como o teria sido omitir os de Gatsby em $O$ Grande Gatsby. Naquele teria resultado em irrele-
N.T. S.F. Fitzgerald Sonhos de Inverno, trad. H. Silva Letro, Lisboa, Relógio d'Água, s/d. 
vância, enquanto neste teria causado uma falta de clareza. De fato, alguns críticos desse romance argumentaram que ele é muito curto ainda que tenha causado no leitor a indispensável sensação de verossimilhança e necessidade, mas essa é outra questão. (Outra queixa um pouco diferente foi levantada contra For Whom The Bells Tolls - Por Quem os Sinos Dobram - que parece muito longo a alguns críticos em relação ao tamanho da ação.)

Há uma segunda diferença que diz respeito à amplitude entre ações dinâmicas que não correspondem ao que examinamos sobre mudanças de maior ou menor importância. Uma mudança simples move gradativamente seu protagonista de uma situação a outra sem inversões e é assim, desde que ponha em ação apenas uma linha causal, uma ação menor do que uma mudança complexa, que mostra seu protagonista passando de uma situação para outra e ainda para uma terceira situação em oposição à segunda e que, assim, projeta em ação diversas linhas causais. O anterior, tendo conseqüentemente menos partes, pode ter uma narração mais breve.

Todas as ações dinâmicas analisadas até agora são exemplos do tipo complexo enquanto “An Outpost of Progress", de Joseph Conrad, ilustra uma mudança simples. As personagens virtuosas de Kayerts e Carlier, inicialmente fracas e frívolas, se deterioram rápida e seguramente quando trazidas ao ácido teste do contato íntimo e prolongado "com a pura exasperada selvageria" no coração da África. Se um conto pode lidar com o desenvolvimento de uma personagem, ele pode também lidar, obviamente, com sua degeneração.É interessante contrastar essa história com "Heart of Darkness" (“O Coração das Trevas”), no qual, tornando Kurtz um modelo de caráter íntegro antes de se render ao abismo, Conrad se propõe a um trabalho muito mais árduo. Mas ele atinge resultados mais intensos, pois, se a queda de Kayerts e Carlier é mais provável, é também, por isso mesmo, menos interessante. No entanto, a segunda história é quase três vezes mais longa do que a primeira (a grande extensão de "O
Coração das Trevas", incidentalmente, pode ser também explicada pelo seu narrador "ruminante" - um tópico que retomaremos adiante).

Assim, por pedir mais efeitos, uma ação dinâmica tende a ser mais longa do que uma estática; uma mudança maior, por incluir necessariamente mais aspectos da vida do protagonista, tende a ser mais longa do que uma mudança menor; e uma mudança complexa, por ter mais partes, tende a ser mais longa do que uma simples. Mas nossos princípios devem ser continuamente abrandados a cada detalhe pois, como veremos adiante, estamos lidando com um conjunto de variáveis independentes. Uma história que deveria ser longa de uma maneira pode, na verdade, ser curta de outra; uma história envolvendo uma mudança significativa, por exemplo, e que deveria ser mais longa do que uma que envolva uma mudança menor, não havendo diferenças, pode, na verdade, tornar-se curta por haver diferenças.

Logo, um conto pode ser curto porque sua ação é inerentemente pequena. Mas, conforme foi indicado, um conto pode englobar uma ação mais longa e continuar a ser curto. Se um escritor decidir-se a representar uma trama, ele tem uma opção a mais como quanto à maneira pela qual ele quer fazê-lo. E aqui ele será guiado pelo seu desejo de maximizar a vivacidade de seu efeito, por um lado, e por atingir esse efeito com a maior economia de meios, por outro. Para começar, ele pode decidir que, apesar de uma determinada parte de sua trama ser relevante, ele fará melhor omitindo-a e deixando-a para inferência.

Desde que essa questão de seleção foi discutida apenas em termos do quanto uma ação completa é posta diante do leitor, e desde que definimos "ação completa" apenas genericamente, é necessário fazer uma pausa para aclarar nossas concepções aqui descritas. Uma ação completa é, como vimos, uma ação de certo tamanho - seja um discurso, cena, episódio ou trama-contendo o que quer que seja relevante para conduzir o protagonista em etapas verossímeis ou necessárias desde o começo, passando 
pelo meio e indo até o final de uma determinada situação.

A questão a ser examinada agora se refere a quantas dessas partes são de fato mostradas ao leitor e quantas são meramente aludidas ou deixadas para inferência. Em "Flight" ("A Fuga"), de Steinbeck, por exemplo, um até então inepto rapaz, como resultado de sua primeira visita sozinho à cidade, é forçado a provar-se homem - a ponto de encarar bravamente a morte. No entanto, na própria narração da história, Steinbeck escolheu omitir completamente a viagem do rapaz até Monterey, trazendoa à tona apenas mais tarde, quando ele retorna e conta à sua mãe o que aconteceu, antes de fugir para as montanhas.

Estamos lidando com uma ação complexa e dinâmica: quais são as partes necessárias para que tal ação atinja o seu efeito desejado?

Uma mudança complexa envolve trazer o protagonista de uma situação a outra por meio de inversão. Por isso, para sua clareza e convicção são necessários: 1) motivo introdutório para apresentá-lo em sua situação original; 2) uma reviravolta para representar as consequiências dessa situação; 3) um motivo incitante que irá servir para movê-lo em direção a uma situação oposta; 4) uma ação progressiva para representá-lo num processo de mudança; e 5) um clímax no qual o processo estará completo (3).

Uma mudança simples, como vimos, envolve levar o protagonista de uma situação a outra sem uma inversão e, assim, requer apenas os três últimos itens esquematizados acima. E princípios semelhantes, no que se refere à seleção, podem ser aplicados em ações estáticas em função de situações únicas e de causas relevantes que revelam.

Vamos ver como esse esquema funciona em "Flight": 1) o rapaz é mandado para Monterey em busca de remédio por sua mãe; 2) ele usa o chapéu e a sela de seu pai, gabando-se de sua recém-adquirida virilidade, e em Monterey bebe muito vinho e arruma briga; 3 ) ele mata um homem e precisa ou encarar as conseqüências como um homem ou fugir e se esconder "como um fraco"; 4) ele volta para casa, conta para sua mãe o que houve, e se prepara para sua jornada e passa por imensa privação durante quatro dias nas montanhas; 5) finalmente, ele morre com honra por encarar, em suas últimas forças, seus perseguidores, aceitando a vingança deles. A maior parte do item 2 e algo do 3 foram omitidos. Por quê?

Podemos afirmar, em primeiro lugar, que isso ocorre porque a verossimilhança exige que o protagonista conte a sua mãe o que aconteceu, Steinbeck simplesmente agiu de acordo com os interesses da economia, evitando repetições. No entanto, essa é quase uma explicação mecânica, apesar de ser, a seu modo, suficientemente pertinente. Mais importante, podemos inferir que Steinbeck tinha como intenção suscitar em nós um misto de compaixão e admiração pelo rapaz conforme sua história se desenrola-compaixão por seu sofrimento e morte, admiração pela nobre maneira pela qual ele sofre e morre. Sendo este o caso, podemos inferir um pouco mais: que ele omitiu a maior parte da reviravolta e do incidente incitante pois, em seu esforço por angariar a simpatia do leitor, ele procurou conscientemente evitar mostrar seu protagonista agindo de modo insensato, sem pensar e de modo fatídico. Omitindo esses trechos, ele também nos impressiona mais vividamente com o surpreendente contraste entre imaturidade e maturidade no comportamento do protagonista desde o momento em que parte de manhã até àquele em que ele retorna à noite. Assim, ele fica livre para concentrar a maior parte da atenção do leitor sobre a nobreza e o sofrimento do rapaz, mais do que sobre sua imprudência e imaturidade. Contudo, devemos ainda saber o que aconteceu em Monterey, já que o rapaz foge para as montanhas, e de que ponto de vista podemos considerar esses acontecimentos. E conseguimos tudo isso através da narração do rapaz a sua mãe: o fato de ele contar a ela sem hesitação ou evasão é um sinal de sua verdadeira maturidade. Ele foi insultado e por isso ele matou antes de perceber o que estava fazendo.

\footnotetext{
Termos e conceitos similares foram utilizados por Paul Good man em seu livro Structure of Literature (Chicago, 1954|, mas de modo ligeiramente diferente. Cheguei às minhas conclusões de modo independente, antes de ter lido esse brilhante mas intrigante livro.
} 
Assim, sua morte no final é plausível por um lado e admirável, por outro.

Nesse sentido, um contraste instrutivo com a sabedoria de Steinbeck é proporcionado por uma adaptação dessa história para a televisão que, por acaso, vi já há algum tempo. Diante de problemas técnicos completamente diferentes, o escritor da televisão procurou ampliar o texto original não apenas incluindo aquelas partes da ação que foram omitidas no original, mas também as estendendo e expandindo ainda mais. $\mathrm{O}$ rapaz é mostrado em Monterey - era um festival e ele se envolve com uma moça e nós o vemos sendo insultado e matando um homem. O festival permitiu a inclusão (intrusão seria um termo melhor) de algumas produções de dança assim como um cintilar de interesse romântico. A fuga propriamente dita foi manipulada do modo mais honesto possível; mas ainda assim as limitações do medium criaram a necessidade do desastrado expediente de trazer o rapaz falando consigo mesmo durante o seu sofrimento já que ele estava, claro, sozinho e o narrador ficcional foi sacrificado de sua função. O efeito geral foi confuso, para dizer o mínimo: as partes relevantes são apenas o insulto e o assassinato, de modo que a dança e a moça, mesmo que tenham sido forjadas pelo fato de o rapaz ter sido insultado, simplesmente tornaram-se nada em função do resto da história; e, mesmo com o insulto e o assassinato, ficou, na verdade, muito desordenado ver o herói derramar sangue e o subseqüente esforço em obter nossas simpatias pelo seu sofrimento nas montanhas foi, conseqüentemente, invalidado. Talvez por causa da brevidade do original e sua correspondente dependência da flexibilidade narrativa, a versão dramatizada de "Flight" foi condenada desde o início.

O que importa aqui é que a história pode ser curta não porque sua ação é inerentemente curta, mas porque o autor escolheu - ao trabalhar com um episódio ou trama omitir certas partes dela. Em outras palavras, uma ação pode ser longa em tamanho e continuar a ser curta na narração, pois nem tudo está lá. Essas lacunas podem estar no início da ação, em algum lugar ao longo de seu desenvolvimento, no seu final, ou alguma outra combinação. Correspondentemente, uma ação pode ser longa na narração porque mais do que suas partes relevantes foram incluídas.

Uma vez que o autor decide quais partes, daquelas que são relevantes, irá incluir, ele pode ter uma segunda opção quanto à escala pela qual ele irá representá-las. Uma determinada ação pode ser estendida na narração pela expansão de suas partes, ou encurtada pela contração. Isso sugere que todas as coisas que de fato "ocorrem" ou são apresentadas numa certa cena - tais como diálogos, solilóquios, gestos, movimentos físicos, vestimentas, cenários de fundo -, o autor pode desdobrá-las passo a passo; ou pode resumi-las e mencionar apenas os pontos culminantes. A escala contraída abstrai retrospectivamente do acontecimento o que é necessário para avançar a história e apresentá-la de modo condensado, enquanto numa escala expandida tenta dar a ilusão de que tudo está sendo apresentado diretamente em detalhes, tal como acontece. A escala contraída tende a cobrir uma ação de um período de tempo longo num espaço relativamente pequeno, enquanto a escala expandida tende a cobrir um período de tempo curto num espaço relativamente amplo. E, claro, tudo isso é uma questão de grau.

No entanto, flexibilidade é uma das primeiras virtudes do meio ficcional e a maioria das narrativas, sejam longas ou breves, varia a escala de apresentação para se adequar ao efeito. Economia e intensidade guiam o autor aqui assim como antes. Mas agora o princípio da proporção também é importante. Aquelas partes da ação que são mais importantes do que outras -e isto, é claro, está relacionado em cada caso ao efeito desejado - deveriam naturalmente ser enfatizadas por meio de uma representação expandida e aquelas que são menos importantes deveriam sercondensadas.

Apesar de a quantidade de tempo ficcional coberto pela ação não ter, como veremos, nenhuma conexão necessária com a extensão de seu tratamento, podemos afirmar que há uma correlação geral, e o escri- 
tor que lida com ações que cobrem um pequeno período de tempo escolherá normalmente as de menor extensão com as quais poderá trabalhar. A regra da economia diz ao autor que, se a substância de sua história se passa dentro do espaço de uma hora, então uma única cena será suficiente. Da mesma forma, se a história cobre muitas horas, um dia ou uma semana, então um episódio poderá ser necessário. Se cobre um ano, ou anos, então é o caso de uma trama. No entanto, Ulysses, de Joyce, inverte essa correlação pela expansão de um único dia num longo romance, compreen-

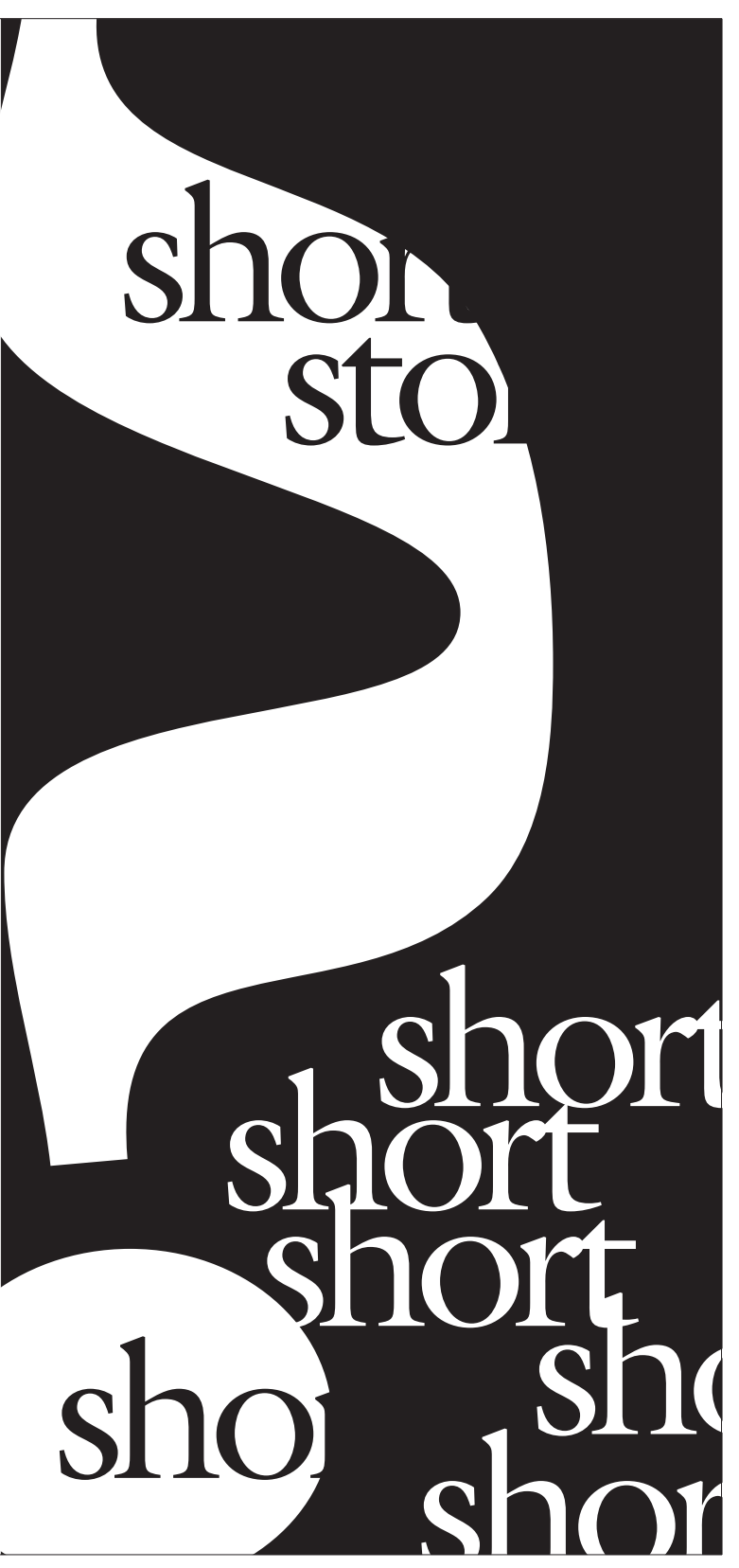

dendo muitos episódios, o que mais uma vez enfatiza que estamos lidando com um conjunto de variáveis independentes.

Por outro lado, "A Morte de Ivan Ilitch" é um bom exemplo, que pode ser encontrado, de uma trama completa e total condensada ao tamanho de um conto - embora um pouco longo. Possui doze seções de tamanhos diferentes numeradas, com alguns flash-backs, mostrando seu protagonista desde a infância até sua morte, já na meia-idade, incluindo aí sua formação educacional, namoro, casamento, carreira e filhos. Toda a história culmina com a primeira e decisiva consciência de Ivan, enquanto ele morre, da realidade da morte e, conseqüentemente, da falsidade de toda sua vida. Evidentemente, para que essa mudança atinja o leitor com inteligibilidade e forças adequadas, toda a vida de Ivan deve ser mostrada. Isto é, o impacto da descoberta de Ivan depende, por sua vez, do conhecimento de como sua vida foi vivida anteriormente e dentro de que valores e atitudes.

Mas "Ivan Ilitch" é curto (relativamente) porque, apesar de uma trama completa e um pouco mais ser representada, ela o é,em grande parte, em uma escala condensada. Da mesma forma, Ulysses, apesar de cobrir um período de tempo muitíssimo menor, é muito mais longo pois sua ação é expandida a cada detalhe (obviamente).

No entanto, economia continua a ser o princípio geral desses casos. Apesar de toda a vida de Ivan precisar ser mostrada, ela é, assim como o próprio personagem, repetitiva e superficial (e este é exatamente o ponto, claro) e se fosse mostrada em sua escala máxima teria enfadado os leitores ao extremo - embora, certamente, Tolstoi tenha representado as partes mais importantes de sua trama numa escala expandida.Joyce também fez o que deveria ter feito para conseguir o efeito desejado, embora seja algo inteiramente diferente. Desde que o trabalho torna-se um irônico contraste entre o que o homem é e o que ele deveria ser, é precisamente a mediocridade e a trivialidade da vida cotidiana que Joyce precisa enfatizar. Por conseguinte, uma quase 
infinita expansão serve ao propósito de Joyce, mas teria embaraçado Tolstoi a atingir o seu.

Outro instrutivo contraste entre esses dois extremos é encontrado na comparação entre "Ivan Ilyitch", que utiliza, como vimos, um alto grau de contração,e "White Elephants", que é quase tão expandido quanto uma única cena entre duas pessoas num período de aproximadamente $30 \mathrm{mi}$ nutos poderia ser. As razões para essa diferença já devem estar claras: Tolstoi tem uma ação longa para ser mostrada, mas a maior parte é importante na medida em que esclarece algo nas poucas cenas finais, enquanto Hemingway tem apenas uma cena para mostrar e assim ele o faz. Logo, a história pode ser curta, mesmo que englobe uma ação longa, pois muito dessa ação é melhor representada numa escala contraída.

Finalmente, podemos considerar como a escolha do ponto de vista está relacionada à questão do tamanho (4). Se um autor decide, por exemplo, dar ao seu narrador completa onisciência, então muitas coisas irão naturalmente daí resultar. Esse narrador poderá editorar, como em Tom Jones, ou Guerra e Paz, e isso irá aumentar significativamente o tamanho do trabalho. Dado esse tipo de onisciência, esse narrador poderá analisar os motivos e estados mentais das personagens com certa minúcia e esse comentário e exposição também irá acrescentar algo ao tamanho do trabalho. Essa é a razão pela qual Thomas Mann, em "Disorder and Early Sorrow", parece abranger mais elementos à primeira vista do que na verdade engloba num estudo mais detido: apesar de tomar quase duas horas para ser lido, de fato, inclui uma ação cujo período de tempo cobre apenas da tarde ao anoitecer de um dia. No entanto, por essa razão a ação é mostrada através de uma tela de exposiçãoe comentários que se referem aos estados mentais do professor e, apesar de a ação externa ser rara, como conseqüência, é mostrada diretamente e numa escala expandida, a história - apesar de curta - é um pouco longa em proporção ao período de tempo coberto pela ação.
Onisciência envolve, por outro lado, características favoráveis à brevidade. Quer dizer, um narrador que existe por toda e acima da ação pode exercer, como dizem, forças amplas e arbitrárias em questões de escala e seleção. Por ele não estar restringido por nenhuma limitação "mortal", ele pode manipular seu material à vontade. Logo, ele pode mudar a cena de uma ação no tempo e no espaço; e, o mais importante para o assunto em questão, pode omitir e/ ou acrescentar partes da ação que não merecem um tratamento mais explícito ou detalhado. No fim das contas, a onisciência é caracterizada por sua flexibilidade e está igualmente bem acomodada em romances e contos.

Um personagem narrador pode também ser inclinado a tecer comentários e especulações, como Marlow em “O Coração das Trevas", e isso igualmente pode acrescentar algo ao tamanho do trabalho. O ponto de vista dramático, de modo similar, pois é comprometido, por definição, a uma escala expandida, como num palco, tende a ser algo mais extenso. Assim, um autor que escolhe o método dramático para um conto fará um trabalho melhor, primeiramente, com uma ação mais curta; ou, se lidar com uma ação mais longa, o fará omitindo certas partes.

Para concluir, uma história pode ser curta porque sua ação é intrinsecamente curta, ou porque sua ação, sendo longa, é reduzida em tamanho por meio de recursos de seleção, escala ou ponto de vista. Ninguém pode dizer de antemão que, se uma história é curta, ela o é porque tem um certo número de palavras ou porque tem mais unidade ou porque enfoca mais no clímax do que no desenvolvimento. Tudo o que podemos fazer, além de reconhecer sua brevidade, é perguntar como e por quê, mantendo simultaneamente equilibradas em nossas mentes as maneiras alternativas de responder a essas questões e suas possíveis combinações. Desse modo, podemos ganhar uma compreensão ampliadae, por consequiência, apreciação das qualidades artísticas específicas dessa curiosa e esplêndida, apesar de excessivamente subestimada, arte. 